\title{
Enhanced visible light photocatalysis through fast crystallization of zinc oxide nanorods
}

\author{
Sunandan Baruah, Mohammad Abbas Mahmood, Myo Tay Zar Myint, \\ Tanujjal Bora and Joydeep Dutta*
}

\author{
Full Research Paper \\ Address: \\ Center of Excellence in Nanotechnology, School of Engineering and \\ Technology, Asian Institute of Technology, Klong Luang, Pathumthani \\ 12120, Thailand. Phone: +66 2524 5680, Fax: +66 25245617 \\ Email: \\ Sunandan Baruah - sunandan@ait.ac.th; Joydeep Dutta* - \\ joy@ait.asia \\ * Corresponding author \\ Keywords: \\ defects; nanoparticle; nanorod; photocatalysis; pollutant; $\mathrm{ZnO}$
}

\author{
Beilstein J. Nanotechnol. 2010, 1, 14-20. \\ doi:10.3762/bjnano.1.3 \\ Received: 23 August 2010 \\ Accepted: 26 October 2010 \\ Published: 22 November 2010 \\ Associate Editor: J. J. Schneider \\ (C) 2010 Baruah et al; licensee Beilstein-Institut. \\ License and terms: see end of document.
}

\begin{abstract}
Hydrothermally grown $\mathrm{ZnO}$ nanorods have inherent crystalline defects primarily due to oxygen vacancies that enhance optical absorption in the visible spectrum, opening up possibilities for visible light photocatalysis. Comparison of photocatalytic activity of $\mathrm{ZnO}$ nanorods and nanoparticle films on a test contaminant methylene blue with visible light irradiation at 72 kilolux (klx) showed that $\mathrm{ZnO}$ nanorods are $12-24 \%$ more active than $\mathrm{ZnO}$ nanoparticulate films. This can be directly attributed to the increased effective surface area for adsorption of target contaminant molecules. Defects, in the form of interstitials and vacancies, were intentionally created by faster growth of the nanorods by microwave activation. Visible light photocatalytic activity was observed to improve by $\approx 8 \%$ attributed to the availability of more electron deficient sites on the nanorod surfaces. Engineered defect creation in nanostructured photocatalysts could be an attractive solution for visible light photocatalysis.
\end{abstract}

\section{Introduction}

Photocatalysis is a light induced catalytic process whereby photogenerated electron-hole pairs in a semiconductor undergo redox reactions with molecules adsorbed onto the surface, thereby breaking them into smaller fragments. Photocatalysis with metal-oxide-semiconductor nanostructures has been an area of intense research over the last couple of decades with titania $\left(\mathrm{TiO}_{2}\right)$ receiving the most attention [1-4]. Optical absorption in the ultraviolet region (peaking around $220 \mathrm{~nm}$ ) [5] and low photoefficiency $[6,7]$ are factors that deter the wide scale use of $\mathrm{TiO}_{2}$ for photocatalytic activities under sunlight. Zinc oxide $(\mathrm{ZnO})$, with a high surface reactivity owing to a large number of native defect sites arising from oxygen nonstoichiometry, has emerged to be an efficient photocatalyst material compared to other metal oxides [8-10]. $\mathrm{ZnO}$ exhibits comparatively higher reaction and mineralization rates [11] and can generate hydroxyl ions more efficiently than titania $\left(\mathrm{TiO}_{2}\right)$ [12]. Surface area and surface defects play an important role in the photocatalytic activity of metal-oxide nanostructures, as the 
contaminant molecules need to be adsorbed on to the photocatalytic surface for the redox reactions to occur. The higher the effective surface area, the higher will be the adsorption of target molecules leading to better photocatalytic activity. One dimensional nanostructures, such as nanowires and nanorods, offer higher surface to volume ratio compared to nanoparticulate coatings on a flat plate [13]. The design of transition metaloxide mesostructures has also been an area of interest for researchers $[14,15]$ owing to high porosity of such structures. The effective surface area (adsorbed amount of target molecules) and the diffusivity are important indexes to gauge photocatalytic activity [14]. Doping of metal oxides with metals and/ or transition metals creates quasi-stable energy states within the band gap (surface defects) [16], thereby affecting the optical and electronic properties [17]. Increased electron trapping due to higher defect sites leads to enhancement in the photocatalytic efficiency. This increase in photocatalytic efficiency is possible provided the electron-hole pair recombination rate is lower than the rate of electron transfer to adsorbed molecules. There are reports on the enhancement of visible light absorption in $\mathrm{ZnO}$ by doping with, e.g., cobalt (Co) [18], manganese $(\mathrm{Mn})$ [19], lead $(\mathrm{Pb})$ and silver $(\mathrm{Ag})$ [16], etc. Photocatalytic activity comparable to doped $\mathrm{ZnO}$ was also observed with engineered defects in $\mathrm{ZnO}$ crystals achieved by fast crystallization during synthesis of the nanoparticles [20].

Results from photocatalysis experiments carried out using $\mathrm{ZnO}$ nanoparticles prepared through a slow growth process $(3 \mathrm{~h}$ hydrolysis at $60^{\circ} \mathrm{C}$ ) and rapid crystallization ( 7 min under microwave irradiation) have already been reported in a previous publication [20]. A higher optical absorption in the visible region was observed in this case. The faster degradation of methylene blue (MB) in the presence of nonstoichiometric crystallites of $\mathrm{ZnO}$ prepared through fast crystallization can be attributed to quasi-stable surface states that enhance the photocatalytic activity. Time correlated single photon count spectroscopy (TCSPCS) carried out on conventionally synthesized and rapidly crystallized nanoparticles clearly demonstrated that a higher rate of injection of photoexcited electrons occurs in the molecules adsorbed on the surface of defect engineered nanoparticles [21]. Upon excitation of $\mathrm{ZnO}$ nanoparticles with high-energy laser pulses at $375 \mathrm{~nm}$ in the presence of MB molecules, a quick decay in photoluminescence in the fast-crystallized particulate samples as compared to the conventionally hydrolyzed ones was observed. The spectroscopic results support the observation that surface defect states are created when the $\mathrm{ZnO}$ crystals are grown rapidly, which facilitates surface reactions such as photocatalysis. Even though the $\mathrm{ZnO}$ nanoparticles could efficiently carry out photocatalytic degradation of MB, the removal of the 5-7 nm sized particles after the completion of the photocatalytic reactions is cumbersome. This necessitates the use of supports for the photocatalysts. In this work we have used glass slides as the support for $\mathrm{ZnO}$ nanorod photocatalysts. When affixed on to a support, $\mathrm{ZnO}$ nanorods offer higher surface to volume ratio compared to nanoparticulate films, allowing higher adsorption of the target molecules [20].

Nonstoichiometric growth of the $\mathrm{ZnO}$ crystal was achieved by microwave heating that offers numerous advantages over conventional autoclave heating, such as rapid rise to crystallization temperatures, homogenous nucleation and fast supersaturation by rapid dissolution [22-27]. In this work a study is conducted on the improvement of visible light photocatalytic degradation of a model organic dye, methylene blue, with $\mathrm{ZnO}$ nanorods grown by a rapid growth process using microwave irradiation.

\section{Results and Discussion}

The $\mathrm{ZnO}$ nanoparticles obtained through the sol-gel synthesis (see section Experimental) are shown in Figure 1a and Figure $1 \mathrm{~b}$ as transmission electron microscopy (TEM) micrographs. The low-resolution TEM micrograph exhibits spherical nanoparticles with diameters of 5 to $7 \mathrm{~nm}$ in size (Figure 1a). Measurements of the lattice fringe widths on the high-resolution

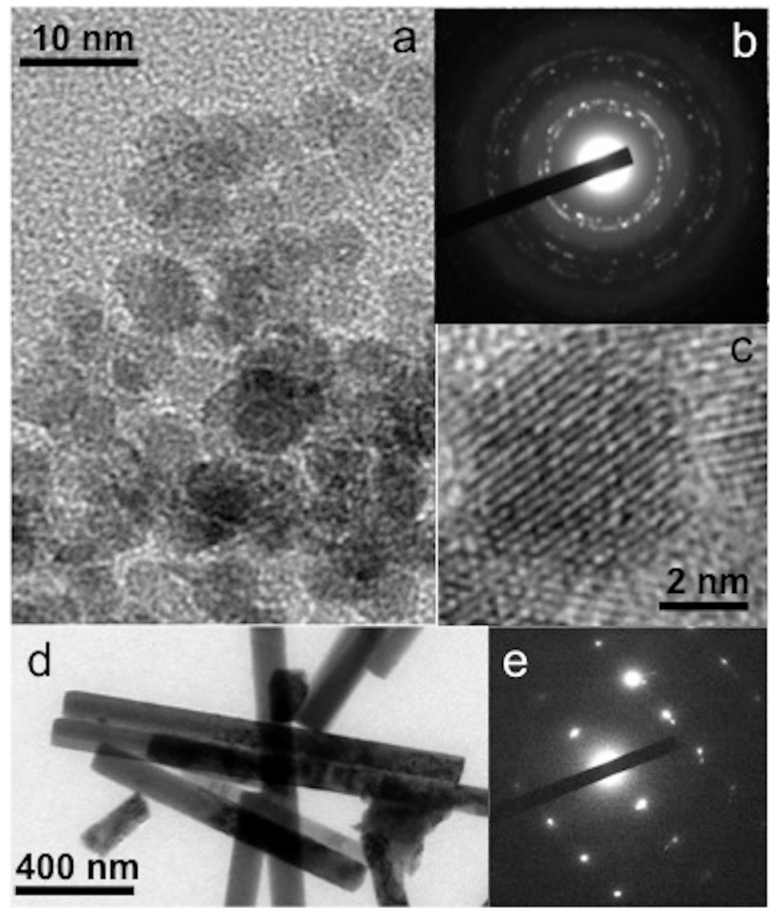

Figure 1: (a) Low-resolution TEM micrograph of $\mathrm{ZnO}$ nanoparticles, (b) electron diffraction pattern of the $\mathrm{ZnO}$ nanoparticles, (c) highresolution TEM micrograph of a $\mathrm{ZnO}$ nanoparticle showing the lattice fringes, (d) low-resolution TEM micrograph of $\mathrm{ZnO}$ nanorods, and (e) electron diffraction pattern taken on a single $\mathrm{ZnO}$ nanorod. 


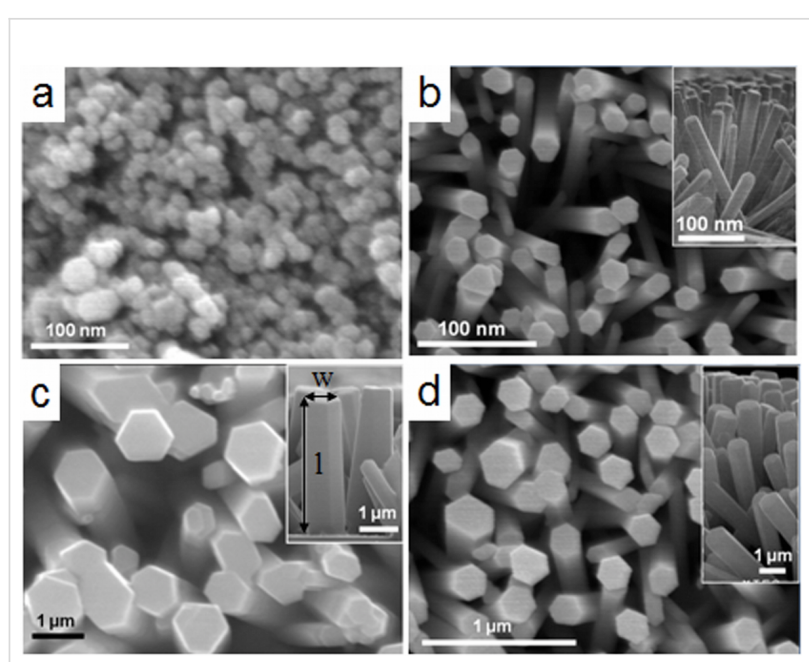

Figure 2: Scanning electron micrograph of (a) $\mathrm{ZnO}$ nanoparticle thin film on glass substrate, (b) Sample $1(0.1 \mathrm{mM})$, inset: cross-sectional view, (c) Sample 2 (1.0 mM), inset: cross-sectional view, and (d) Sample 3 (10.0 mM), inset: cross-sectional view.

TEM micrographs (see Figure 1c) confirm the wurtzite structure of the zinc oxide crystallites. Fringe widths of $0.28 \mathrm{~nm}$, $0.16 \mathrm{~nm}$ and $0.19 \mathrm{~nm}$ measured on different images show the dominance of the (100), (110) and (102) planes. The electron diffraction pattern shown in Figure $1 \mathrm{~b}$ also confirms the crystallinity of the $\mathrm{ZnO}$ nanoparticles. A TEM micrograph of $\mathrm{ZnO}$ nanorods collected from the glass substrate is shown in Figure 1d. The diffraction pattern taken on a single rod is shown in Figure 1e demonstrating a single crystalline structure.

The width, length and density of the nanorods on the substrates are dependent on the synthesis conditions, such as, seeding of the substrates, concentration of precursors in the growth solution, as well as the duration of hydrothermal process [2729]. The effective surface area available for dye adsorption is a function not only of the thickness and length of the nanorods, but also the density of the rods covering the substrate. The average exposed surface area was approximated from measurements using the scanning electron micrographs (Figure 2) considering regular hexagonal $\mathrm{ZnO}$ nanorods. The free surface

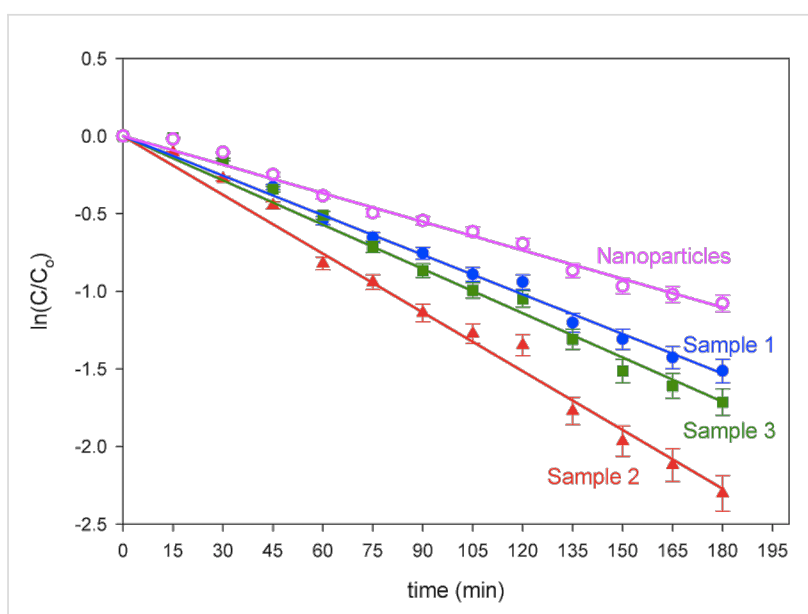

Figure 3: Degradation of methylene blue as a function of $\ln \left(C / C_{0}\right)$ versus the time of exposure to visible light on the $\mathrm{ZnO}$ nanoparticle film and the nanorods with different dimensions.

area available for dye adsorption was estimated with the expression

$$
S A=\left[\frac{1}{4}\left(3 \sqrt{3} w^{2}\right)+3 w l\right] d
$$

where $S A$ is the total surface area, $w$ is the average width, $l$ the average length and $d$ the number density of the $\mathrm{ZnO}$ nanorods on the substrate. In Table 1 the estimated values of the exposed surface area available for adsorption of the dye molecules in the different samples are presented.

Figure 3 shows the photocatalytic results comparing the $\mathrm{ZnO}$ nanoparticle film and the nanorods of different sizes and density (thereby offering different surface to volume ratios) on glass substrate $\left(3 \mathrm{~cm}^{2}\right)$. The photocatalytic degradation of MB could be fitted using Equation 2 and the apparent rate constants $(k=a b)$ were calculated from the linear curves using Equation 3:

$$
\frac{C}{C_{0}}=a e^{-b t}
$$

Table 1: Estimated effective area of $\mathrm{ZnO}$ nanorod surfaces on substrates of size $1 \times 3 \mathrm{~cm}$, grown at different reactant concentrations during the

\begin{tabular}{|c|c|c|c|}
\hline Parameter & Sample 1 & Sample 2 & Sample 3 \\
\hline Growth concentration & $0.1 \mathrm{mM}$ & $1.0 \mathrm{mM}$ & $10.0 \mathrm{mM}$ \\
\hline Average width of nanorod $w(\mathrm{~nm})$ & 20 & 200 & 1000 \\
\hline Average length of nanorod $I(\mathrm{~nm})$ & 150 & 1800 & 5000 \\
\hline Area of each nanorod $\left(\mu \mathrm{m}^{2}\right)$ & 0.00952 & 1.132 & 16.3 \\
\hline Number density of the nanorods on substrate $\left(\mu \mathrm{m}^{-2}\right)$ & 1200 & 14 & 0.8 \\
\hline Total effective surface area on a substrate of size $1 \times 3 \mathrm{~cm}\left(\mathrm{~cm}^{2}\right)$ & 34.27 & 47.54 & 39.12 \\
\hline
\end{tabular}
hydrothermal growth process at $90{ }^{\circ} \mathrm{C}$ with equimolar concentrations of zinc nitrate and hexamine in the starting aqueous solution. 


$$
\ln \left(\frac{C}{C_{0}}\right)=-(a b) t=-k t
$$

The nanoparticle film demonstrated minimum photocatalytic activity as expected owing to lower surface $\left(S A \approx 6 \mathrm{~cm}^{2}\right)$ exposed to the contaminant molecules [10]. After $180 \mathrm{~min}$ of visible light illumination at $72 \mathrm{klx}$, the nanoparticulate thin film showed minimum activity (degradation efficiency of $64 \%$ after $180 \mathrm{~min} ; k=0.005993 \mathrm{~min}^{-1}$ ). Sample 2 with the maximum surface area $\left(47.54 \mathrm{~cm}^{2}\right)$ gave the highest activity (degradation efficiency of $90 \% ; k=0.012792 \mathrm{~min}^{-1}$ ) and sample 1 with the minimum surface area among the nanorod samples $\left(34.27 \mathrm{~cm}^{2}\right)$ had the lowest activity (degradation efficiency of $78 \%$; $k=$ $0.008412 \mathrm{~min}^{-1}$ ).

As with the $\mathrm{ZnO}$ nanoparticles [17,18], an increase in the density of vacancies and interstitial defects in the nanorod crystals were obtained through accelerated crystallization using microwaves and subsequent fast quenching reactions. Apart from the oxygen nonstoichiometry, microwave induced growth also reduces the growth time. A comparison of the $\mathrm{ZnO}$ nanorod growth using the conventional process and through fast crystallization (with microwave irradiation) is shown in Figure 4 . The width and length of the nanorods were measured after $5 \mathrm{~h}$ growth with starting solutions of $0.1 \mathrm{mM}, 1.0 \mathrm{mM}$ and $10.0 \mathrm{mM}$ zinc nitrate hexahydrate and hexamethylenetetramine at a temperature of $90{ }^{\circ} \mathrm{C}$. An increase in size was observed for the samples prepared by microwave excitation indicating a faster crystallization process. About 40 to $50 \%$ increase in width of the nanorods was noted for the samples prepared by microwave induced hydrolysis reactions. Similarly, an increased length of $\mathrm{ZnO}$ nanorods by 36 to $66 \%$ was obtained for different growth concentrations of the reactant solution.

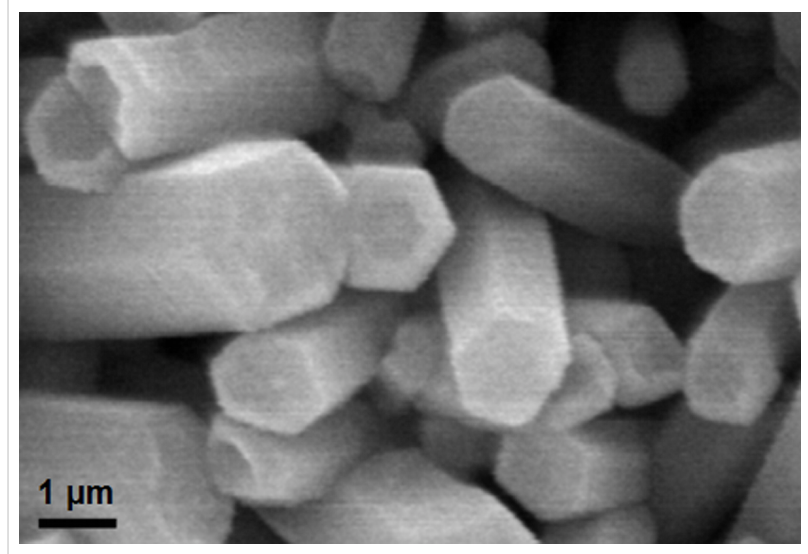

Figure 5: A typical scanning electron micrograph showing the $\mathrm{ZnO}$ nanorods grown using microwave irradiation in a reaction bath containing $10.0 \mathrm{mM}$ zinc nitrate and hexamethylenetetramine for $10 \mathrm{~h}$; structural defects can be observed especially on the polar face.

A typical scanning electron micrograph of $\mathrm{ZnO}$ nanorods grown through fast crystallization in a reaction bath containing 10.0 $\mathrm{mM}$ zinc nitrate hexahydrate and hexamethylenetetramine with microwave irradiation for $10 \mathrm{~h}$ is shown in Figure 5. Visible structural defects can be clearly observed on the surface of the rods. In order to further confirm if the fast synthesis route creates increased electron deficient sites, two samples with comparable exposed surface areas, one prepared by the conventional process (Sample 2 with surface area $\approx 47.54 \mathrm{~cm}^{2}$ ) and the other by fast hydrolysis (surface area $\approx 33.74 \mathrm{~cm}^{2}$ ), were selected. Sample 2 was selected as it showed maximum activity compared to Sample 1 and Sample 3. The fast hydrolyzed sample was grown using a reaction bath at a concentration of $10.0 \mathrm{mM}$ of zinc nitrate and hexamine for $4 \mathrm{~h}$ under microwave illumination. Optical absorption spectra of the two samples (Figure 6: inset) show higher absorption in the rapidly crystal-

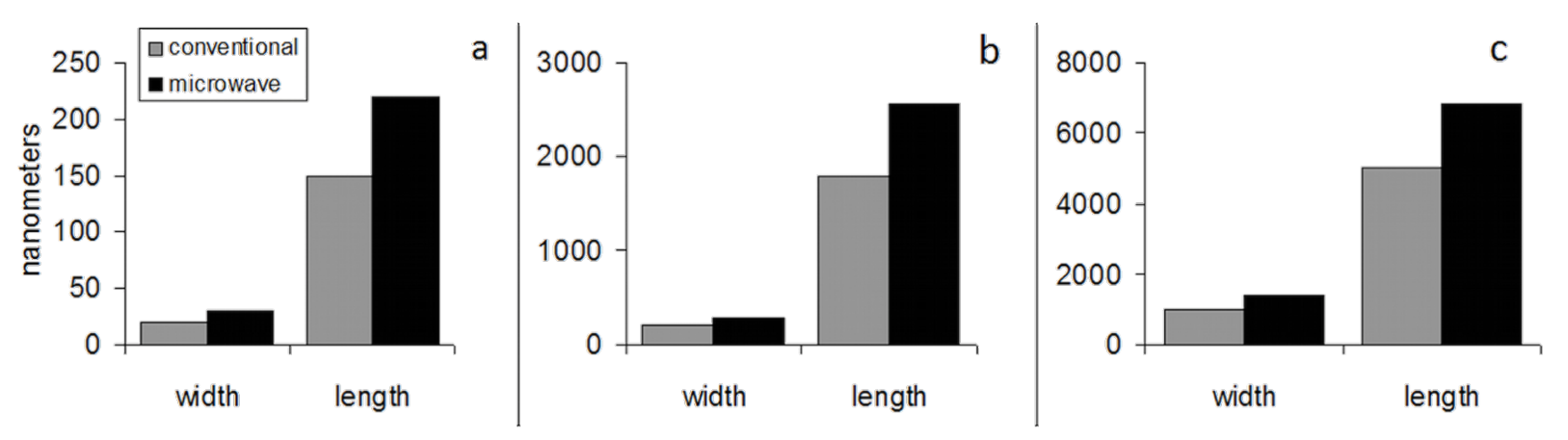

Figure 4: Increase in width and length resulting from fast crystallization by the use of microwave irradiation after $10 \mathrm{~h}$ growth at different growth concentrations: (a) $0.1 \mathrm{mM}$, (b) $1.0 \mathrm{mM}$, and (c) $10.0 \mathrm{mM}$. 
lized nanorods especially in the near UV and visible regions of the electromagnetic spectrum up to about $500 \mathrm{~nm}$. The optical absorptions of both the samples are comparable above $500 \mathrm{~nm}$.

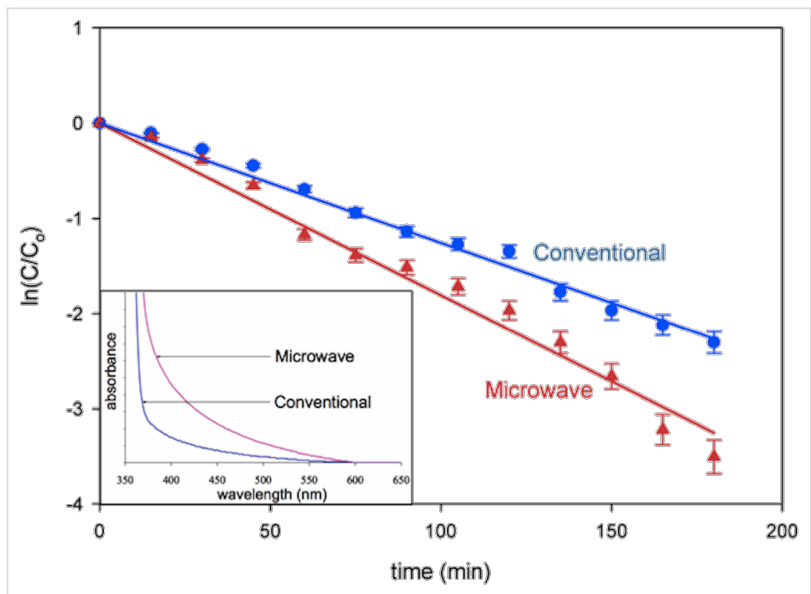

Figure 6: Degradation of methylene blue as a function of $\ln \left(\mathrm{C} / \mathrm{C}_{0}\right)$ versus the time of exposure to light in the presence of $\mathrm{ZnO}$ nanorods synthesized by the conventional method (Sample 2 with surface area $\approx$ $47.54 \mathrm{~cm}^{2}$ ) and the fast crystallization method (surface area $\approx 33.74$ $\mathrm{cm}^{2}$ ). Inset: UV-vis absorption spectra of $\mathrm{ZnO}$ nanorods grown by the conventional hydrothermal method and by microwave irradiation of comparable exposed surface area.

The microwave hydrolyzed nanorods demonstrated better photocatalytic activity (degradation efficiency of $97 \%$ in 180 $\left.\min ; k=0.019481 \mathrm{~min}^{-1}\right)$ as compared to the conventionally synthesized rods (degradation efficiency of $90 \%$ in $180 \mathrm{~min} ; \mathrm{k}=$ $0.012792 \mathrm{~min}^{-1}$ ) (Figure 6). This is attributed to the higher density of electron deficient sites generated during microwave synthesis that can trap photogenerated electrons and reduce recombinations, thereby improving the photocatalytic activity. $\mathrm{ZnO}$ nanorods grown through fast crystallization under microwave irradiation not only creates defective crystallites ideal for photocatalysis (Figure 3), but this growth process is also faster compared to the conventional process, thereby saving time and energy during the growth process.

\section{Conclusion}

One-dimensional nanostructures with very high surface to volume ratio can be attractive candidates for photocatalysis. Comparative results of photocatalytic degradation studies on methylene blue with visible light irradiation demonstrated that $\mathrm{ZnO}$ nanorods are $12-24 \%$ more active than nanoparticulate films. An enhancement of $8 \%$ in the photocatalytic activity of $\mathrm{ZnO}$ nanorods was achieved through engineered creation of oxygen deficient structures using a fast crystallization process achieved by microwave assisted hydrolysis. This enhancement in the photocatalytic activity was correlated to an increased absorption efficiency of light in the UV and visible regions. Intentional defect inclusion in the crystal of $\mathrm{ZnO}$ nanostruc- tures during synthesis is an attractive option for visible light photocatalysis and further results with different pollutants will be presented in succeeding reports. $\mathrm{ZnO}$, apart from having specific structural properties, can also be grown on any type of substrates, such as glass, alumina, polyethylene, polypropylene, steel, cotton, amongst others, through proper seeding and hence is suitable for a large number of applications, e.g., wastewater treatment, etc. that is scalable for practical uses.

\section{Experimental Materials used}

Zinc acetate dihydrate $\left[\left(\mathrm{CH}_{3} \mathrm{COO}\right)_{2} \mathrm{Zn} \cdot 2 \mathrm{H}_{2} \mathrm{O}\right.$, Merck $]$, sodium hydroxide $[\mathrm{NaOH}$, Merck], zinc nitrate hexahydrate $\left[\mathrm{Zn}\left(\mathrm{NO}_{3}\right)_{2} \cdot 6 \mathrm{H}_{2} \mathrm{O}\right.$, APS Ajax Finechem], hexamethylenetetramine $\left[\left(\mathrm{CH}_{2}\right)_{6} \mathrm{~N}_{4}\right.$, Carlo Erba], ethanol $\left[\mathrm{C}_{2} \mathrm{H}_{5} \mathrm{OH}, \mathrm{J} . \mathrm{T}\right.$. Baker], and methylene blue $\left[\mathrm{C}_{16} \mathrm{H}_{18} \mathrm{~N}_{3} \mathrm{CIS} \cdot 3 \mathrm{H}_{2} \mathrm{O}\right.$, Carlo Erba].

\section{Synthesis of $\mathrm{ZnO}$ nanoparticles}

$\mathrm{ZnO}$ nanoparticles were synthesized in a colloidal solution with ethanol as the solvent. The co-precipitation technique has been reported in previous publications from our group [19,30]. Briefly, $40 \mathrm{~mL}$ of $2 \mathrm{mM}$ zinc acetate solution was heat treated at $70{ }^{\circ} \mathrm{C}$ for half an hour. Then $20 \mathrm{~mL}$ of $4 \mathrm{mM} \mathrm{NaOH}$ solution in deionised water was added and the admixture was hydrolyzed for $2 \mathrm{~h}$ at $60{ }^{\circ} \mathrm{C}$.

\section{Growth of ZnO Nanorods}

The $\mathrm{ZnO}$ nanorods were grown hydrothermally on glass substrates, which were initially thiolated for better attachment of the $\mathrm{ZnO}$ nanoparticle seeds [31]. Hydrothermal growth of $\mathrm{ZnO}$ nanostructures is a simple and thermally efficient process [27]. Seeding was done by dip coating with a colloidal solution of $\mathrm{ZnO}$ nanoparticles and annealed at $100{ }^{\circ} \mathrm{C}$ for $30 \mathrm{~min}$. The seeds served as nucleation sites and the $\mathrm{ZnO}$ nanorods grew preferentially along the c-axis of the wurtzite structure when the seeded substrate was placed in an aqueous chemical bath containing equimolar zinc nitrate hexahydrate and hexamethylenetetramine maintained at $90{ }^{\circ} \mathrm{C}$ [31]. Three different growth concentrations were used: (1) Sample 1: $0.1 \mathrm{mM}$, (2) Sample 2: $1.0 \mathrm{mM}$ and (3) Sample 3: $10.0 \mathrm{mM}$. The growth of the nanorods was continued for $20 \mathrm{~h}$ and the chemical bath was replenished with fresh reactants every five hours to maintain the growth rate [20]. The substrate was then removed and washed several times with deionised water and then annealed at $250{ }^{\circ} \mathrm{C}$ for $1 \mathrm{~h}$ to remove any unreacted organic deposits. Microwave synthesis of $\mathrm{ZnO}$ nanorods on seeded substrates was carried out in a commercial microwave oven operated at the low energy mode for $5 \mathrm{~h}$. Quantification of nanorod size and density were carried out with Scion image processing software on Scanning Electron Microscopy (SEM) obtained from a JEOL JSM-6301F operated at $20 \mathrm{kV}$. 


\section{Photocatalysis Tests}

Photocatalysis was conducted with a popular test contaminant, methylene blue, which is a heterocyclic aromatic compound, in aqueous solution. Photocatalytic degradation of methylene blue $\left[\mathrm{C}_{16} \mathrm{H}_{18} \mathrm{~N}_{3} \mathrm{SCl}\right](\mathrm{MB})$ results in the formation of leuco-methylene blue (LMB). A $10 \mu \mathrm{M}$ solution of MB was prepared in deionised water and put in polymethyl methacrylate (PMMA) cuvettes and a glass slide $(3 \times 1 \mathrm{~cm})$ with a coating of nanorods (Sample 1, Sample 2 and Sample 3) was placed inside the cuvette with the nanorod surface facing a tungsten-halogen light source $(500 \mathrm{~W})$. A glass vessel containing water was placed between the light source and the cuvettes to absorb the UV and infrared light radiated by the lamp. At the sample position, 72 klx of light was measured by a luxmeter calibrated to $550 \mathrm{~nm}$. As a control, a similar glass slide $(3 \times 1 \mathrm{~cm})$ covered with a thin film of $\mathrm{ZnO}$ nanoparticles (diameter $\approx 5-7 \mathrm{~nm}$ ) by a dip coating process was placed in a cuvette with the nanoparticle side facing the light source. Optical absorption spectra were recorded after different light exposure durations with an Ocean Optics spectrophotometer in order to monitor the rate of decolourisation of the test contaminant. The degradation of the dye was estimated from the reduction in absorption intensity of $\mathrm{MB}$ at a fixed wavelength $\lambda_{\max }=665 \mathrm{~nm}$. The degradation efficiency (DE) was then calculated as given in Equation 4:

$$
D E=\frac{I_{0}-I}{I_{0}} \times 100=\frac{C_{0}-C}{C_{0}} \times 100
$$

where $I_{0}$ is the initial absorption intensity of MB at $\lambda_{\max }=665$ $\mathrm{nm}$ and $I$ is the absorption intensity after photoirradiation. $C_{0}$ is the initial concentration of the dye and $C$ is the concentration after photoirradiation.

\section{Acknowledgements}

The authors would like to acknowledge partial financial support from the National Nanotechnology Center, belonging to the National Science \& Technology Development Agency (NSTDA), Ministry of Science and Technology (MOST), Thailand and the Centre of Excellence in Nanotechnology at the Asian Institute of Technology, Thailand.

\section{References}

1. Fujishima, A.; Honda, K. Nature 1972, 238, 37-38. doi:10.1038/238037a0

2. Fujishima, A.; Rao, T. N.; Tryk, D. A. J. Photochem. Photobiol., C 2000, 1, 1-21. doi:10.1016/S1389-5567(00)00002-2

3. Nozik, A. J.; Memming, R. J. Phys. Chem. 1996, 100, 13061-13078. doi:10.1021/jp953720e

4. Fernández-lbáñez, P.; Blanco, J.; Malato, S.; De Las Nieves, F. J. Water Res. 2003, 37, 3180-3188. doi:10.1016/S0043-1354(03)00157-X
5. Martyanov, I. N.; Savinov, E. N.; Klabunde, K. J. J. Colloid Interface Sci. 2003, 267, 111-116. doi:10.1016/S0021-9797(03)00678-7

6. Wilson, E. Chem. Eng. News 1996, 74, 29-33.

7. Cabrera, M. I.; Alfano, O. M.; Cassano, A. E. J. Phys. Chem. 1996, 100, 20043-20050. doi:10.1021/jp962095q

8. Ali, A. M.; Emanuelsson, E. A. C.; Patterson, D. A. Appl. Catal., B 2010, 97, 168-181. doi:10.1016/j.apcatb.2010.03.037

9. Pardeshi, S. K.; Patil, A. B. J. Mol. Catal. A: Chem. 2009, 308, 32-40. doi:10.1016/j.molcata.2009.03.023

10. Qamar, M.; Muneer, M. Desalination 2009, 249, 535-540. doi:10.1016/j.desal.2009.01.022

11. Poulios, I.; Makri, D.; Prohaska, X. Global NEST 1999, 1, 55-62.

12. Carraway, E. R.; Hoffman, A. J.; Hoffmann, M. R. Environ. Sci. Technol. 1994, 28, 786-793. doi:10.1021/es00054a007

13. Hornyak, G. L.; Dutta, J.; Tibbals, H. F.; Rao, A. Introduction to nanoscience; CRC Press: Boca Raton, 2008.

14. Kimura, T.; Yamauchi, Y.; Miyamoto, N. Chem.-Eur. J. 2010, 16, 12069-12073. doi:10.1002/chem.201001251

15. Liu, G.; Sun, C.; Yang, H. G.; Smith, S. C.; Wang, L.; Lu, G. Q.; Cheng, H. M. Chem. Commun. 2010, 46, 755-757. doi:10.1039/b919895d

16. Wang, R.; Xin, J. H.; Yang, Y.; Liu, H.; Xu, L.; Hu, J. Appl. Surf. Sci. 2004, 227, 312-317. doi:10.1016/j.apsusc.2003.12.012

17. Vanheusden, K.; Warren, W. L.; Voigt, J. A.; Seager, C. H.; Tallant, D. R. Appl. Phys. Lett. 1995, 67, 1280-1282. doi:10.1063/1.114397

18. Colis, S.; Bieber, H.; Begin-Colin, S.; Schmerber, G.; Leuvrey, C.; Dinia, A. Chem. Phys. Lett. 2006, 422, 529-533. doi:10.1016/j.cplett.2006.02.109

19. Ullah, R.; Dutta, J. J. Hazard. Mater. 2008, 156, 194-200. doi:10.1016/j.jhazmat.2007.12.033

20. Baruah, S.; Rafique, R. F.; Dutta, J. NANO 2008, 3, 399-407. doi:10.1142/S179329200800126X

21. Baruah, S.; Sinha, S. S.; Ghosh, B.; Pal, S. K.; Raychaudhuri, A. K.; Dutta, J. J. Appl. Phys. 2009, 105, 074308. doi:10.1063/1.3100221

22. Gedye, R.; Smith, F.; Westaway, K.; Ali, H.; Baldisera, L.; Laberge, L.; Rousell, J. Tetrahedron Lett. 1986, 27, 279-282. doi:10.1016/S0040-4039(00)83996-9

23. Wang, W. W.; Zhu, Y. J. Inorg. Chem. Commun. 2004, 7, 1003-1005. doi:10.1016/j.inoche.2004.06.014

24. Huang, J.; Xia, C.; Cao, L.; Zeng, X. Mater. Sci. Eng., B 2008, 150, 187-193. doi:10.1016/j.mseb.2008.05.014

25. Ma, M. G.; Zhu, Y. J.; Cheng, G. F.; Huang, Y. H. Mater. Lett. 2008, 62, 507-510. doi:10.1016/j.matlet.2007.05.072

26. Peiro, A. M.; Ayllon, J. A.; Peral, J.; Domenech, X.; Domingo, C. J. Cryst. Growth 2005, 285, 6-16. doi:10.1016/j.jcrysgro.2005.07.028

27. Baruah, S.; Dutta, J. Sci. Technol. Adv. Mater. 2009, 10, 013001. doi:10.1088/1468-6996/10/1/013001

28. Baruah, S.; Dutta, J. J. Sol-Gel Sci. Technol. 2009, 50, 456-464. doi:10.1007/s10971-009-1917-2

29. Baruah, S.; Dutta, J. J. Cryst. Growth 2009, 311, 2549-2554. doi:10.1016/j.jcrysgro.2009.01.135

30. Sugunan, A.; Warad, H. C.; Boman, M.; Dutta, J. J. Sol-Gel Sci. Technol. 2006, 39, 49-56. doi:10.1007/s10971-006-6969-y

31. Claesson, E. M.; Philipse, A. P. Colloids Surf., A 2006, 297, 46-54. doi:10.1016/j.colsurfa.2006.10.019 


\section{License and Terms}

This is an Open Access article under the terms of the Creative Commons Attribution License

(http://creativecommons.org/licenses/by/2.0), which permits unrestricted use, distribution, and reproduction in any medium, provided the original work is properly cited.

The license is subject to the Beilstein Journal of Nanotechnology terms and conditions:

(http://www.beilstein-journals.org/bjnano)

The definitive version of this article is the electronic one which can be found at:

doi:10.3762/bjnano.1.3 